\title{
Streptomyces lactacystinicus sp. nov. and Streptomyces cyslabdanicus sp. nov., producing lactacystin and cyslabdan, respectively
}

\author{
Akira Také, Atsuko Matsumoto, Satoshi Ōmura and Yōko Takahashi
}

The Journal of Antibiotics (2015) 68, 719; doi:10.1038/ja.2015.89

Correction to: The Journal of Antibiotics (2015) 68, 322-327; doi:10.1038/ja.2014.162; published online 10 December 2014

The authors of the above article noticed following error in the publication of this paper.
In the Abstract and the 'Description of Streptomyces lactacystinicus sp. nov.' sub-section under the Results and Discussion section, DSM number for strain OM-6519 $9^{\mathrm{T}}$ was wrong. It should have been read OM-6519 ${ }^{\mathrm{T}}$ ( = NBRC $110082^{\mathrm{T}}$, DSM $42136^{\mathrm{T}}$ ).

Authors apologize for this mistake. 